BECKER, Luciana Rosa. A metodologia da pesquisa no direito e o paradigma emergente de Boaventura de Sousa Santos. Revista Eletrônica Direito e Política, Programa de Pós-Graduação Stricto Sensu em Ciência Jurídica da UNIVALI, Itajaí, v.10, n.3, 20 quadrimestre de 2015. Disponível em: www.univali.br/direitoepolitica - ISSN 1980-7791.

\title{
A METODOLOGIA DA PESQUISA NO DIREITO E O PARADIGMA EMERGENTE DE BOAVENTURA DE SOUSA SANTOS
}

\author{
THE METHODOLOGY OF RESEARCH ON THE LAWS AND EMERGING \\ PARADIGM OF BOAVENTURA DE SOUSA SANTOS
}

Luciana Rosa Becker ${ }^{1}$

SUMÁRIO: Introdução; 1 De regresso às perguntas simples; 2 O Paradigma Dominante; 3 A Crise Epistemológica do Paradigma Dominante; 40 Paradigma Emergente; 5 Aplicação do pensamento de Boaventura de Sousa Santos na metodologia da pesquisa em direito; Considerações finais; Referências das Fontes Citadas.

\section{RESUMO}

Boaventura é um pensador de múltiplas identidades: professor universitário, cientista social, jurista, autor de diversas obras, filósofo da ciência, ativista e poeta. Seu pensamento filosófico gira em torno da crise paradigmática das ciências naturais e sociais, ao passo que aponta o surgimento dos sinais de um paradigma emergente. A pesquisa jurídica brasileira deve atentar-se para a valiosa contribuição do pensamento do autor.

PALAVRAS-CHAVE: Boaventura; Metodologia; Pesquisa; Direito; Paradigma Emergente.

\begin{abstract}
Boaventura is a thinker of multiple identities: a university professor, social scientist, jurist, author of several works, a philosopher of science, activist and poet. His philosophical thought revolves around the crisis paradigm of natural and social sciences, while it points out the emergence of signs of an emerging paradigm. The Brazilian legal research should pay attention to the valuable contribution of the author's thought.
\end{abstract}

KEYWORDS: Boaventura; Methodology; Research; Law. Emerging paradigm.

1 Bacharel em Direito pela Universidade Passo Fundo (UPF). Mestrando em Direito pela Universidade de Passo Fundo (UPF), Especialista em Direito do Trabalho e Processo do Trabalho pela Faculdade Meridional (IMED). E-mail: lucianarosabecker@hotmail.com. 
BECKER, Luciana Rosa. A metodologia da pesquisa no direito e o paradigma emergente de Boaventura de Sousa Santos. Revista Eletrônica Direito e Política, Programa de Pós-Graduação Stricto Sensu em Ciência Jurídica da UNIVALI, Itajaí, v.10, n.3, 20 quadrimestre de 2015. Disponível em: www.univali.br/direitoepolitica - ISSN 1980-7791.

\section{INTRODUÇÃO}

O ensinamento científico do autor português Boaventura de Sousa Santos é de extrema importância para a pesquisa da ciência jurídica. Em suma, o pensamento filosófico de Boaventura de Sousa Santos consiste em demonstrar que o conhecimento científico encontra-se em uma fase de transição paradigmática, em que o paradigma dominante enfrenta uma crise irreversível, momento no qual surgem, os sinais de um paradigma emergente, pautado na supressão da dicotomia sujeito/objeto, além de outras características.

Diante disto, o presente trabalho abordará as reflexões de Boaventura de Sousa Santos e a sua contribuição à metodologia da pesquisa no direito, o que facilita a inserção da ciência jurídica no paradigma da pós-modernidade.

\section{DE REGRESSO ÀS PERGUNTAS SIMPLES}

No ano de 1750, Rousseau, na Academia de Dijon, formula e responde questões acerca das ciências e dos cientistas: "O progresso das ciências e das artes contribuirá para purificar ou para corromper os nossos costumes?" ${ }^{2}$ Em plena Revolução Industrial, a Academia esperava ouvir que a ciência era, sim, purificadora dos costumes. Entretanto Rousseau trouxe em seu "Discurso sobre as Ciências e as Artes" uma dura crítica ao avanço científico, apontando-o como o grande responsável pela corrupção moral e política da Europa antecipando, assim, o pensamento de Nietzsche ${ }^{3}$, quando este diz que Sócrates, ao inaugurar

\footnotetext{
2 SANTOS, Boaventura de Souza. Para um novo senso comum: a ciência, o direito e a política na transição paradigmática. 5. ed. São Paulo: Cortez, 2005. v.1. p. 59.

${ }^{3}$ Nietzsche faz forte criticas ao pensamento socrático, para ele, Sócrates teria contribuído para os rumos funestos da cultura e consequentemente, do homem. Sócrates foi um grande racionalista, sua máxima residia no famoso "conheça-te a ti mesmo" que em essência expressa uma alta valorização da consciência e da racionalidade enquanto elementos que nos permitem acessar o que é o "bom" e o "ruim". Por outro lado, para Nietzsche, a consciência é algo que surge da necessidade do homem viver em sociedade, sendo a linguagem um órgão a serviço da consciência que também surgiu das necessidades da vida coletiva. Dessa forma, o homem está limitado ao desconhecido.
} 
BECKER, Luciana Rosa. A metodologia da pesquisa no direito e o paradigma emergente de Boaventura de Sousa Santos. Revista Eletrônica Direito e Política, Programa de Pós-Graduação Stricto Sensu em Ciência Jurídica da UNIVALI, Itajaí, v.10, n.3, 20 quadrimestre de 2015. Disponível em: www.univali.br/direitoepolitica - ISSN 1980-7791.

o racionalismo e questionar os valores tradicionais gregos, contribuía para a ruína da religião, da estrutura social em prol de um individualismo inconsequente.

Esse racionalismo socrático teve seu auge com a Revolução Industrial e passou a criar um novo paradigma (ou senso comum): a de que a ciência moderna era a fonte de todo o saber e que sem ela o homem não conseguiria sobreviver.

Boaventura de Souza Santos, entretanto, assegura que esse paradigma da ciência moderna está sendo suprido por outro. Qual? Por quê? Eis um questionamento do autor: "como é que a ciência moderna, em vez de erradicar os riscos, as opacidades, as violências e as ignorâncias, que dantes eram associadas à pré-modernidade, está de fato a recriá-los numa forma hipermoderna " $^{4}$. É por isso que Boaventura afirma que durante muitos séculos o homem deixou de fazer perguntas simples, como as feitas por Rousseau, e se deixou levar pelas ideologias da ciência moderna. No entanto, isso passou a mudar. Por quê? Antes de responder o porquê, o autor caracteriza a sociedade contemporânea:

Em minha opinião, o que mais nitidamente caracteriza a condição sócio-cultural deste fim de século é a absorção do pilar da emancipação pelo da regulação, fruto da gestão reconstrutiva dos défices e dos excessos da modernidade confiada à ciência moderna e, em segundo lugar, ao direito moderno ${ }^{5}$.

O autor coloca a sociedade sobre três pilares: o Estado (cuja grande ferramenta é o Direito), o Mercado (onde a regulação pelas grandes empresas transnacionais é a forma de controle) e a Comunidade (esquecida, desvalorizada e dominada pelas ideologias de que um mercado absolutamente liberal, um Estado mínimo e ciência poderão trazer a paz perpétua). O Neoliberalismo dominou as décadas de oitenta e noventa do século passado, épocas em que o pensamento de

\footnotetext{
${ }^{4}$ SANTOS, Boaventura de Souza. Para um novo senso comum: a ciência, o direito e a política na transição paradigmática. v.1. p. 58.

${ }^{5}$ SANTOS, Boaventura de Souza. Para um novo senso comum: a ciência, o direito e a política na transição paradigmática. v.1. p. 55.
} 
BECKER, Luciana Rosa. A metodologia da pesquisa no direito e o paradigma emergente de Boaventura de Sousa Santos. Revista Eletrônica Direito e Política, Programa de Pós-Graduação Stricto Sensu em Ciência Jurídica da UNIVALI, Itajaí, v.10, n.3, 20 quadrimestre de 2015. Disponível em: www.univali.br/direitoepolitica - ISSN 1980-7791.

Boaventura foi mais difundido, pois este não concordava com as políticas neoliberais e via as universidades públicas como as grandes prisioneiras desse sistema, pois estavam impedidas de fazer pesquisa que mostrassem as falhas da ciência e do sistema capitalista como um todo, pois as verbas só iam para as pesquisas que gerassem lucro imediato.

Foi nessa situação, por exemplo, que as políticas neoliberais de presidentes como FHC foram um duro choque nas universidades públicas que não se adaptassem ao modelo vigente. É bem verdade que o pensamento de Boaventura foi aceito nas décadas seguintes, basta ver que as políticas sociais e preocupadas com as universidades voltaram, ao menos, às pautas governamentais.

Assim, o pilar "Comunidade" foi deixado de lado, impedido de emancipar-se, de superar problemas como desemprego, fome, miséria, deixado de lado em prol de uma regulação econômica onde o Estado, a Ciência e o Direito constituem-se em armas que impedem as classes menos favorecidas de enxergarem as ideologias dominantes.

Contudo, refaz-se a pergunta feita anteriormente: por que, repentinamente, esse paradigma, ou senso comum, vem sendo substituído (pelo novo senso comum)? E que novo senso comum é esse? Pergunta essa que será respondida mais adiante, ao tratar-se da crise epistemológica do paradigma dominante. A seguir, no próximo tópico, uma breve análise a respeito do paradigma dominante.

\section{O PARADIGMA DOMINANTE}

A ciência moderna firma seu alicerce na revolução científica do século $X V$, e se desenvolveu nos séculos seguintes com base no domínio das ciências naturais. Para Boaventura, as ciências sociais a partir do século XIX. passaram a compor:

um modelo global (isto é, ocidental) de racionalidade científica que admite variedade interna, mas que se defende ostensivamente de duas formas de conhecimento não científico (e portanto, potencialmente perturbadoras): o 
BECKER, Luciana Rosa. A metodologia da pesquisa no direito e o paradigma emergente de Boaventura de Sousa Santos. Revista Eletrônica Direito e Política, Programa de Pós-Graduação Stricto Sensu em Ciência Jurídica da UNIVALI, Itajaí, v.10, n.3, $2^{\circ}$ quadrimestre de 2015. Disponível em: www.univali.br/direitoepolitica - ISSN 1980-7791.

senso comum e as chamadas humanidades ou estudos humanísticos (em que se incluiriam, entre outros, os estudos históricos, filológicos, jurídicos, literários, filosóficos e teológicos) ${ }^{6}$.

Esse modelo de racionalidade científica pode também ser considerado um modelo totalitário, pois só são cabíveis ao seu domínio as abordagens teóricas e metodológicas pautadas intrinsecamente aos seus pressupostos epistemológicos.

No campo das ciências sociais, em meados do século XIX, se desenvolveram duas correntes, a primeira tem como expoente Durkheim, que acreditava que o correto era aplicar os princípios epistemológicos das ciências naturais nas ciências sociais. Essa corrente teórica metodológica entendia que apesar das diferenças de conteúdo entre as ciências naturais e sociais, estas últimas deveriam ser estudas como as primeiras, se aproximando com os critérios da biologia e da física.

A segunda corrente, defendida por Weber, instituiu um método próprio para as ciências sociais, este que exclusivamente deveria ser distinto do método das ciências da natureza. Essa segunda corrente defendia um método próprio para as ciências sociais, pois não é possível explicar o comportamento humano pelas mesmas leis observáveis das ciências da natureza. A ciência social será sempre essa ciência subjetiva e não objetiva como as ciências naturais, tem de compreender os fenômenos sociais a partir das atitudes mentais e do sentido que os agentes conferem às suas ações, para o que é indispensável utilizar métodos de investigação e mesmo critérios epistemológicos diferentes das correntes nas ciências naturais.

Certamente, as duas correntes acabaram trazendo mais relevância às ciências da natureza do que mesmo às ciências sociais. Entretanto, o ponto de vista weberiano antipositivista se estabelece como a gênese de uma ruptura com o paradigma dominante da ciência moderna.

\footnotetext{
${ }^{6}$ SANTOS, Boaventura de Souza. Para um novo senso comum: a ciência, o direito e a política na transição paradigmática. v.1. p. 60.
} 
BECKER, Luciana Rosa. A metodologia da pesquisa no direito e o paradigma emergente de Boaventura de Sousa Santos. Revista Eletrônica Direito e Política, Programa de Pós-Graduação Stricto Sensu em Ciência Jurídica da UNIVALI, Itajaí, v.10, n.3, 20 quadrimestre de 2015. Disponível em: www.univali.br/direitoepolitica - ISSN 1980-7791.

\section{A CRISE EPISTEMOLÓgICA DO PARADIGMA DOMINANTE}

Atualmente, são muito intensos os sinais de que o modelo de racionalidade científica descrito no item anterior sofre uma intensa crise. Boaventura aqui aponta três traços principais dessa crise:

Primeiro, que essa crise é não só profunda como é irreversível; segundo, que estamos a viver um período de revolução científica que se iniciou com Einstein e a mecânica quântica e não se sabe ainda quando acabará; terceiro, que os sinais nos permitem tão-só especular acerca do paradigma que emergirá deste período revolucionário, mas que, desde já, pode afirmar-se com segurança que colapsarão as distinções em que assenta o paradigma dominante a que aludi atrás. ${ }^{7}$

A ciência da Modernidade, iniciada ainda na Idade Média com Francis Bacon, que teve seu auge, com as várias revoluções industriais e chegou à contemporaneidade com a cibernética, a informática, passa a não ser o paradigma absoluto, perdendo espaço para outras formas de conhecimentos, da mesma maneira que o neoliberalismo perde espaço dentro de alguns países capitalistas.

Uma série de condições teóricas e sociais pode ser conferida para a crise do paradigma dominante da ciência moderna. São quatro condições de caráter teórico:

a) A teoria da relatividade de Einstein: Desde Newton, Copérnico e Galileu a ciência buscou princípios e leis universais e absolutas: a Mecânica de Newton provou que os corpos se atraem, que toda ação exige necessariamente uma reação, que tudo que há no espaço mantém uma lei lógica que pode ser entendida, medida e usada para o proveito humano.

\footnotetext{
${ }^{7}$ SANTOS, Boaventura de Souza. Para um novo senso comum: a ciência, o direito e a política na transição paradigmática. v.1. p. 68.
} 
BECKER, Luciana Rosa. A metodologia da pesquisa no direito e o paradigma emergente de Boaventura de Sousa Santos. Revista Eletrônica Direito e Política, Programa de Pós-Graduação Stricto Sensu em Ciência Jurídica da UNIVALI, Itajaí, v.10, n.3, 20 quadrimestre de 2015. Disponível em: www.univali.br/direitoepolitica - ISSN 1980-7791.

Esta teoria veio revolucionar as nossas concepções de espaço e de tempo. Não havendo simultaneidade universal, o tempo e o espaço absolutos deixam de existir, a partir de então, os processos se tornam relativos, vindo a refutar o modelo dominante racional do paradigma da ciência moderna que pressupõe que a ordem é estável.

b) A mecânica quântica de Heisenberg e Bohr: Esta mostra o quanto a relatividade está presente na física, Bohr e Heisenberg comprovaram que não é possível analisar um objeto sem interferir nele, sem o modificar, e a tal ponto que o objeto que sai de um procedimento de medição não é igual ao que lá entrou. A abordagem do paradigma emergente no tocante a relação do sujeito com objeto opõe-se ao paradigma dominante (paradigma este que será tratado no próximo item) que tem como proposta o distanciamento, a não interferência no objeto. Na edificação do novo paradigma há uma relação de reciprocidade entre o sujeito e objeto, o sujeito é uma extensão do objeto.

c) A incompletude da matemática demonstrada por Gödel: A Matemática, assim como a escrita, surgiu como uma ferramenta para facilitar o comércio, tendo sua origem na praticidade do dia-a-dia. Entretanto, desenvolveu-se tanto o ponto de tocar na Metafísica, pois já Pitágoras usava-a como algo místico, única capaz de descrever a essência do mundo. No início do século XX ela fundiu-se com a lógica aristotélica e criou uma linguagem que visava algo absoluto e universal, infalível. Entretanto, a Matemática ainda não conseguia dar conta de problemas como o porquê da infinidade dos números, afinal, como pode dentro de um conjunto de números, que por si só já são infinitos, haver vários subconjuntos, também infinitos? A Matemática, sendo o grande pilar da Ciência moderna, é incapaz de fazer aquilo que sua essência lhe impõe, encontrar respostas para tudo de forma exata. Isso, para Boaventura, tira a confiabilidade do paradigma comum a capitalistas e comunistas, liberais e conservadores, ou seja, a crença na Razão como forma única de saber.

d) A ordem a partir da desordem de Prigogine: A quarta causa é formada pelos avanços do conhecimento nos domínios da microfísica, da química e da biologia nos últimos trinta anos. Esta condição é fundamental em 
BECKER, Luciana Rosa. A metodologia da pesquisa no direito e o paradigma emergente de Boaventura de Sousa Santos. Revista Eletrônica Direito e Política, Programa de Pós-Graduação Stricto Sensu em Ciência Jurídica da UNIVALI, Itajaí, v.10, n.3, 20 quadrimestre de 2015. Disponível em: www.univali.br/direitoepolitica - ISSN 1980-7791.

relação a todo processo de crise para emergência do novo paradigma, pois a transdisciplinaridade e interdisciplinaridade possibilitaram um movimento de convergência entre as ciências naturais e sociais, que assim constituiu o paradigma da auto-organização.

As condições sociais visam a refletir as conjunturas política, econômica e social, pois grande parte do fazer científico está concentrada nos países centro de decisões políticas e socioeconômicas e nesse sentido "ciência e tecnologia têm vindo a revelar-se as duas faces de um processo histórico em que os interesses militares e econômicos vão convergindo até quase à indistinção". ${ }^{8}$ Boaventura ainda elucida:

No domínio da organização do trabalho científico, a industrialização da ciência produziu dois efeitos principais. Por um lado, a comunidade cientifica estratificou-se, as relações de poder entre cientistas tornaram-se mais autoritárias e desiguais e a esmagadora maioria dos cientistas foi submetida a um processo de proletarização no interior dos laboratórios e dos centros de investigação. Por outro lado, a investigação capital-intensiva ( assente em instrumentos caros e raros) tornou impossível o livre acesso ao equipamento, o que contribuiu para o aprofundamento do fosso, em termos de desenvolvimento científico e tecnológico, entre os países centrais e os países periféricos. ${ }^{9}$

Essas condições teóricas e sociais tendem por consequências a construírem um novo paradigma, um paradigma científico reformulado (conhecimento prudente) e um paradigma de cunho social (conhecimento para uma vida decente).

\section{O PARADIGMA EMERGENTE}

\footnotetext{
${ }^{8}$ SANTOS, Boaventura de Sousa. Um discurso sobre as ciências. 15. ed. Porto: Afrontamento, 2007. p.35.

9 SANTOS, Boaventura de Sousa. Um discurso sobre as ciências. 15. ed. Porto: Afrontamento, 2007. p.35.
} 
BECKER, Luciana Rosa. A metodologia da pesquisa no direito e o paradigma emergente de Boaventura de Sousa Santos. Revista Eletrônica Direito e Política, Programa de Pós-Graduação Stricto Sensu em Ciência Jurídica da UNIVALI, Itajaí, v.10, n.3, 20 quadrimestre de 2015. Disponível em: www.univali.br/direitoepolitica - ISSN 1980-7791.

A ciência não sendo mais capaz de garantir o comando ideológico sobre as pessoas, qual o paradigma que surge então? Boaventura diz que a formação do novo paradigma que surge, só pode alcançar-se por meio especulativo:

Eu falarei do paradigma de um conhecimento prudente para uma vida decente. Com esta designação, quero significar que a natureza da revolução cientifica que atravessamos é estruturalmente diferente da que ocorreu no século XVI. Sendo uma revolução científica que ocorre numa sociedade ela própria revolucionada pela ciência, o paradigma a emergir dela não pode ser apenas um paradigma científico (o paradigma de um conhecimento prudente), tem de ser também um paradigma social (o paradigma de uma vida decente). ${ }^{10}$

Portanto, o novo paradigma deve se atentar tanto com as consequências da evolução científica, como também como os problemas sociais que atingem a humanidade. O que Boaventura propõe para a solução deste problema é alterar o destaque dado ao Estado e ao Mercado (no tripé Estado-Mercado-Comunidade) para a Comunidade. Tanto a ciência quanto o Estado e o Direito trabalham como reguladores do homem, naquilo que Foucault chama de panóptico ${ }^{11}$ : o poder não emana de cima para baixo apenas, mas de forma horizontal, todos observam todos, e quem não se enquadra naquilo que é dito pelo Mercado, pelo Estado e pelo Direito é execrado, não apenas por meio de violência física, onde a própria moda seria uma maneira de atribuir novos valores.

\footnotetext{
10 SANTOS, Boaventura de Souza. Para um novo senso comum: a ciência, o direito e a política na transição paradigmática. v.1. p. 74.

11 No final do Séc. XVIII o filósofo e jurista inglês Jeremy Bentham concebeu pela primeira vez a ideia do panóptico. Para isto Bentham estudou "racionalmente", em suas próprias palavras, o sistema penitenciário. Criou então um projeto de prisão circular, onde um observador central poderia ver todos os locais onde houvesse presos. Foi naquele período da história que, segundo o francês Michel Foucault, iniciou-se um processo de disseminação sistemática de dispositivos disciplinares, a exemplo do panóptico. Um conjunto de dispositivos que permitiria uma vigilância e um controle social cada vez mais eficientes, porém, não necessariamente com os mesmos objetivos "racionais" desejados por Bentham e muitos de seus antecessores e contemporâneos.
} 
BECKER, Luciana Rosa. A metodologia da pesquisa no direito e o paradigma emergente de Boaventura de Sousa Santos. Revista Eletrônica Direito e Política, Programa de Pós-Graduação Stricto Sensu em Ciência Jurídica da UNIVALI, Itajaí, v.10, n.3, 20 quadrimestre de 2015. Disponível em: www.univali.br/direitoepolitica - ISSN 1980-7791.

Boaventura diz que esse poder está mudando devido à crise da ciência moderna, do Estado liberal e do Direito positivo, e que parece se voltar para os reais problemas sociais da comunidade, sendo a fraternidade e a solidariedade os pilares desse novo paradigma.

O novo modelo de saber científico que surge, traz consigo uma nova visão de mundo para a sociedade, que tem por base quatro princípios para sustentar o paradigma emergente, enunciado como paradigma do conhecimento prudente para uma vida decente:

\section{a)Todo o conhecimento científico-natural é científico-social}

Nesta Tese o autor sustenta que a distinção entre as ciências naturais e ciências sociais deixou de ter sentido e utilidade, pois todo conhecimento tende a ser um conhecimento não dualista, que se funda na superação das distinções até então aplicadas, tais como natureza/cultura, natural/artificial.

A superação da dicotomia ciências naturais/ciências sociais tenderá a revalorizar os estudos humanísticos, ou seja, a pessoa será entendida enquanto autor e sujeito do mundo, no centro do conhecimento, diferente das humanidades tradicionais porque a natureza está no centro da pessoa.

\section{b) Todo o conhecimento é local e total}

No paradigma emergente há uma crítica à parcelização e disciplinarização do conhecimento científico e a busca pelo conhecimento total. Ou seja, o conhecimento pós-moderno é um conhecimento sobre as condições de possibilidade. Em "Um discurso sobre as Ciências", Boaventura afirma:

Os males desta parcelização do conhecimento e do reducionismo arbitrário que transporta consigo são hoje reconhecidos, mas as medidas propostas para os corrigir acabam em geral por os reproduzir sob outra forma. Criamse novas disciplinas para resolver os problemas produzidos 
BECKER, Luciana Rosa. A metodologia da pesquisa no direito e o paradigma emergente de Boaventura de Sousa Santos. Revista Eletrônica Direito e Política, Programa de Pós-Graduação Stricto Sensu em Ciência Jurídica da UNIVALI, Itajaí, v.10, n.3, 20 quadrimestre de 2015. Disponível em: www.univali.br/direitoepolitica - ISSN 1980-7791.

pelas antigas e por esse via reproduz-se o mesmo modelo de cientificidade. ${ }^{12}$

Nesta perspectiva, o conhecimento é relativamente imetódico, pois forma-se a partir de uma multiplicidade metodológica, numa transgressão metodológica, que não segue um estilo unidimensional, com isso possibilita-se uma maior personalização do trabalho científico.

\section{c) Todo o conhecimento é autoconhecimento}

Neste paradigma assume-se que o objeto é a continuação do sujeito por outros meios e que justamente por isso todo o conhecimento científico é também autoconhecimento. Afirma-se assim a ideia de que a ciência não descobre, cria. Trata-se de um ato criativo protagonizado por cada cientista e pela comunidade científica em seu conjunto. Para Boaventura, "a explicação científica dos fenômenos é a autojustificação da ciência enquanto fenômeno central da nossa contemporaneidade. A ciência é autobiográfica". ${ }^{13} \mathrm{O}$ autor segue explicando que:

No paradigma emergente, o caráter autobiográfico e autoreferenciável da ciência é plenamente assumido. A ciência moderna legou-nos um conhecimento funcional do mundo que alargou extraordinariamente as nossas perspectivas de sobrevivência. Hoje não se trata tento de sobreviver como de saber viver. Para isso é necessário uma outra forma de conhecimento, um conhecimento compreensivo e íntimo que não nos separe e antes nos uma pessoalmente ao que estudamos. A incerteza do conhecimento, que a ciência moderna sempre viu como limitação técnica destinada a sucessivas superações, transforma-se na chave do entendimento de um mundo que mais do que controlado tem de ser contemplado. ${ }^{14}$

12 SANTOS, Boaventura de Sousa. Um discurso sobre as ciências. 15. ed. Porto: Afrontamento, 2007. p.47.

13 SANTOS, Boaventura de Sousa. Um discurso sobre as ciências. 15. ed. Porto: Afrontamento, 2007. p.52.

${ }^{14}$ SANTOS, Boaventura de Sousa. Um discurso sobre as ciências. 15. ed. Porto: Afrontamento, 2007. p.54. 
BECKER, Luciana Rosa. A metodologia da pesquisa no direito e o paradigma emergente de Boaventura de Sousa Santos. Revista Eletrônica Direito e Política, Programa de Pós-Graduação Stricto Sensu em Ciência Jurídica da UNIVALI, Itajaí, v.10, n.3, 20 quadrimestre de 2015. Disponível em: www.univali.br/direitoepolitica - ISSN 1980-7791.

O conhecimento científico ensina a viver e se traduz em um saber prático, surgindo assim, a última característica, o último principio da ciência pósmoderna.

\section{d) Todo o conhecimento científico visa constituir-se em senso comum}

A ciência pós-moderna compreende que nenhuma forma de conhecimento é em si mesma, racional e tenta dialogar com outras formas de conhecimento deixando-se aprofundar por elas. O conhecimento do senso comum é a mais importante, apesar de a ciência moderna ter o considerado superficial ilusório e falso, tendo a ciência pós-moderna, tentado reabilitar o senso comum por reconhecer nele algumas virtudes para enriquecer a relação do homem com o mundo. Boaventura de Souza Santos, afirma que:

A ciência pós-moderna, ao sensocomunizar-se, não despreza
p conhecimento que produz a tecnologia, mas entende que,
tal como o conhecimento se deve traduzir em
autoconhecimento, o desenvolvimento tecnológico deve
traduzir-se em sabedoria de vida. É esta que assinala os
marcos da prudência à nossa aventura cientifica. A
prudência é a insegurança assumida e controlada. ${ }^{15}$

Assim, o que se almeja na ciência pós-moderna é o salto do conhecimento científico para o conhecimento do senso comum, ou seja, o conhecimento científico pós-moderno só se realiza enquanto tal na medida em que se converte em senso comum.

\section{APLICAÇÃO DO PENSAMENTO DE BOAVENTURA DE SOUSA SANTOS NA METODOLOGIA DA PESQUISA EM DIREITO}

A atual ocasião de crise paradigmática que atravessa a ciência moderna faz surgir os sinais de um paradigma emergente, designado por Boaventura de como

${ }^{15}$ SANTOS, Boaventura de Sousa. Um discurso sobre as ciências. 15. ed. Porto: Afrontamento, 2007. p.57. 
BECKER, Luciana Rosa. A metodologia da pesquisa no direito e o paradigma emergente de Boaventura de Sousa Santos. Revista Eletrônica Direito e Política, Programa de Pós-Graduação Stricto Sensu em Ciência Jurídica da UNIVALI, Itajaí, v.10, n.3, 20 quadrimestre de 2015. Disponível em: www.univali.br/direitoepolitica - ISSN 1980-7791.

"paradigma de um conhecimento prudente para uma vida decente", paradigma este que não é apenas científico, como o paradigma dominante da ciência moderna, mas, um paradigma social.

Assim, é esse paradigma emergente que vai guiar a metodologia da pesquisa em Direito, que não poderá mais buscar no racionalismo científico, no determinismo, e no positivismo as bases de fundamentação do conhecimento. Portanto, a metodologia da pesquisa em direito precisa superar a dicotomia entre ciências naturais e ciências sociais, já que, segundo Santos, essa separação não tem mais razão de ser.

No paradigma emergente, são as ciências sociais que influenciam o conhecimento nas ciências naturais. Contudo, chega-se a uma situação paradoxal, as ciências sociais surgiram na ciência moderna adotando a metodologia das ciências naturais. Assim sendo, uma inversão, seria, em tese, nada mais que a aplicação das ciências naturais nas próprias ciências naturais.

A pesquisa em Direito deve revalorizar os estudos humanísticos, ou seja, a passagem paradigmática na ciência do Direito inclui a transformação, mas não o abandono, da dogmática jurídica, buscando-se mais a aplicação da zetética e hermenêutica jurídica. Na pesquisa do Direito, a concepção humanística deve estar no centro do conhecimento, e não fora dele, como ocorre no paradigma dominante.

Assim, na pesquisa em metodologia em Direito há que estar sempre presente a ideia segundo o qual todo o conhecimento científico-natural é científico-social. Entretanto, segundo o pensamento de Boaventura, apenas esse sentimento não é o bastante. A metodologia da pesquisa jurídica deve guiar-se, igualmente, no reconhecimento de que todo conhecimento é local e total.

Pode-se dizer que atualmente, progride-se de forma ainda tímida em direção à constituição do conhecimento local e total que, no perceber de Santos, se materializará no paradigma emergente, com a constituição por meio de galerias temáticas e que, no momento certo, será adotado por grupos sociais concretos, 
BECKER, Luciana Rosa. A metodologia da pesquisa no direito e o paradigma emergente de Boaventura de Sousa Santos. Revista Eletrônica Direito e Política, Programa de Pós-Graduação Stricto Sensu em Ciência Jurídica da UNIVALI, Itajaí, v.10, n.3, 20 quadrimestre de 2015. Disponível em: www.univali.br/direitoepolitica - ISSN 1980-7791.

podendo ser traduzido para outros lugares cognitivos, e utilizado fora do contexto de origem.

Boaventura, entretanto alerta, que esse conhecimento se formará a partir de uma pluralidade de métodos, que só pode ser atingida mediante transgressão, e que levará à aplicação dos métodos de acordo com a necessidade contextual da pesquisa. E é com esse espírito que deve ser desenvolvida a pesquisa jurídica, atentando-se para o fim necessário da distinção entre sujeito e objeto imposta pela ciência moderna, e chamando-se a volta do sujeito para a ciência, conforme sugere Boaventura de Sousa Santos:

Parafraseando Clausewitz, podemos afirmar hoje que o objeto é a continuação do sujeito por outros meios. Por isso, todo conhecimento científico é autoconhecimento. A ciência não descobre, cria, e o ato criativo protagonizado por cada cientista e pela comunidade científica no seu conjunto tem de se conhecer intimamente antes que conheça o que com ele se conhece do real. Os pressupostos metafísicos, os sistemas de crenças, os juízos de valor não estão antes nem depois da explicação científica da natureza ou da sociedade. São parte integrante dessa mesma explicação. A ciência moderna não é a única explicação possível da realidade e não há seque qualquer razão cientifica para a considerar melhor que as explicações alternativas da metafísica, da astrologia, da religião, da arte ou da poesia. A razão por que privilegiamos hoje uma forma de conhecimento assente na previsão e no controle dos fenômenos nada tem de cientifico. É um juízo de valor, A explicação cientifica dos fenômenos é a autojustificação da ciência enquanto fenômeno central da nossa contemporaneidade. A ciência é assim, autobiográfica. ${ }^{16}$

Deste modo, um cientista que, por exemplo, se dispõe a realizar uma análise jurídica do preconceito religioso, ou intolerância religiosa, seguramente estará mergulhado na pesquisa, ficando assim, identificada uma fusão entre o objeto e o sujeito que traz consigo a influência do sistema de crenças ao qual se está submetido ou subordinado.

\footnotetext{
${ }^{16}$ SANTOS, Boaventura de Sousa. Um discurso sobre as ciências. 15. ed. Porto: Afrontamento, 2007. p.52.
} 
BECKER, Luciana Rosa. A metodologia da pesquisa no direito e o paradigma emergente de Boaventura de Sousa Santos. Revista Eletrônica Direito e Política, Programa de Pós-Graduação Stricto Sensu em Ciência Jurídica da UNIVALI, Itajaí, v.10, n.3, 20 quadrimestre de 2015. Disponível em: www.univali.br/direitoepolitica - ISSN 1980-7791.

Isso fica claro em pesquisas que abrangem os aspectos jurídicos da bioética, onde os juízos de valor do pesquisador, e até mesmo suas crenças, vão influenciar diretamente na solução do problema que propõe. Portanto, a pesquisa jurídica em bioética está se mostrando muito condizente com as ideias de Boaventura sobre o paradigma emergente, dado o seu arranjo transdisciplinar entre biologia, medicina, filosofia e direito, e outros.

No paradigma emergente nasce uma característica imprescindível, quiçá o mais relevante sinal para orientar o que será o conhecimento pós-moderno, sinal este que consiste na reaproximação da ciência com o senso comum, uma vez que reconhece neste, qualidades capazes de cooperar categoricamente na procura pelo conhecimento, diversamente do paradigma dominante, onde a ciência se estabeleceu a partir do momento em que rompeu com o senso comum. Assim, Boaventura afirma: "É nesses termos que se concebe o reencontro da ciência com o senso comum. Essa concepção pode formular-se do seguinte modo: uma vez feita a ruptura epistemológica, o ato epistemológico mais importante é a ruptura com a ruptura epistemológica". ${ }^{17}$

Aparentemente, esse reencontro entre ciência com o senso comum pode nos conduzir a conclusões equivocadas, já que indica um retrocesso a um estado anterior ao desenvolvimento da ciência moderna. Porém, Boaventura explica que não é exatamente isso que ocorre:

Tal como sucede com os obstáculos epistemológicos, a dupla ruptura não significa que a segunda neutralize a primeira e que, assim, se regresse ao status quo ante, à situação anterior à primeira ruptura. Se esse fosse o caso, regressarse-ia ao senso comum e todo o trabalho epistemológico seria em vão. Pelo contrário, a dupla ruptura procede a um trabalho de transformação tanto do senso comum como da ciência. Enquanto a primeira ruptura é imprescindível para constituir a ciência, mas deixa o senso comum tal como estava antes dela, a segunda ruptura transforma o senso comum com base na ciência. Com essa dupla transformação pretende-se um senso comum esclarecido e uma ciência

17 SANTOS, Boaventura de Sousa. Introdução a uma ciência pós-moderna. Rio de Janeiro: Graal, 1989. p. 36. 
BECKER, Luciana Rosa. A metodologia da pesquisa no direito e o paradigma emergente de Boaventura de Sousa Santos. Revista Eletrônica Direito e Política, Programa de Pós-Graduação Stricto Sensu em Ciência Jurídica da UNIVALI, Itajaí, v.10, n.3, 20 quadrimestre de 2015. Disponível em: www.univali.br/direitoepolitica - ISSN 1980-7791.

prudente, ou melhor, uma nova configuração do saber que se aproxima da phronesis aristotélica, ou seja, um saber prático que dá sentido e orientação à existência e cria o hábito de decidir bem. ${ }^{18}$

Pode-se concluir então, que no paradigma emergente é incontestável que a realização do conhecimento científico pós-moderno, enquanto tal, apenas ocorre quando direcionado para o senso comum. Portanto, realiza-se o ideal do conhecimento prudente para uma vida decente em razão de que é justamente o senso comum o responsável pela prudência na pesquisa científica, principalmente nas ciências sociais, incluindo-se aí a pesquisa em Direito.

Sob o escudo da ciência moderna, a pesquisa em direito sempre separou o sujeito do objeto da pesquisa e afastou o senso comum da averiguação científica. Já no paradigma emergente, a pesquisa em direito deve incluir o senso comum como fonte de conhecimento verdadeiro, e também valer-se de de uma metodologia tal que o conhecimento derradeiro seja precisamente a "sensocomunização".

Finalmente, objetivou-se demonstrar aqui, que as ponderações metodológicas e epistemológicas de Boaventura de Sousa Santos podem e devem servir como importante fundamentação para o adiantamento da pesquisa em direito, que precisa de uma reformulação para atingir a maior perfeição possível do conhecimento prudente para uma vida decente.

\section{CONSIDERAÇÕES FINAIS}

Atualmente, a ciência vive uma fase de mudança paradigmática, onde, o paradigma dominante, regulado na racionalidade e positivismo científicos, tornou-se insuficiente para responder às questões sobre o enriquecimento ou empobrecimento prático da vida cotidiana. Essa crise da ciência moderna é

18 SANTOS, Boaventura de Sousa. Introdução a uma ciência pós-moderna. Rio de Janeiro: Graal, 1989. p. 41. 
BECKER, Luciana Rosa. A metodologia da pesquisa no direito e o paradigma emergente de Boaventura de Sousa Santos. Revista Eletrônica Direito e Política, Programa de Pós-Graduação Stricto Sensu em Ciência Jurídica da UNIVALI, Itajaí, v.10, n.3, 20 quadrimestre de 2015. Disponível em: www.univali.br/direitoepolitica - ISSN 1980-7791.

irreversível e evoca o nascimento, por via especulativa, dos sinais de um paradigma emergente, chamado de paradigma do conhecimento prudente para uma vida decente. Nesse paradigma emergente, há a superação das dicotomias entre ciências naturais e ciências sociais, e entre sujeito e objeto.

A pesquisa jurídica brasileira deve atentar-se para a valiosa contribuição do pensamento de Boaventura de Sousa Santos, seja em termos metodológicos ou epistemológicos, onde o uso da metodologia proposta por Boaventura de Sousa Santos induz a um conhecimento holístico, capaz de colaborar para a necessária aproximação entre o pesquisador e o mundo social no qual está inserido.

Finalmente, é importante que se faça uma reflexão e que se questione sobre a possibilidade do Direito ser imaginado sob uma nova perspectiva. O futuro do Direito e o futuro dos cursos jurídicos estão justamente no esforço conjunto de se pensar o próprio Direito, não simplesmente como um produto acabado que se autocoloca, de forma impositiva e irracional. É indispensável superar os obstáculos epistemológicos que se colocam diante dos processos de conhecimento do Direito. Uma consciência crítica e reflexiva precisa ser desenvolvida e praticada por todos os agentes do Direito. O discurso dos tempos atuais exige profissionais bem preparados, ou seja, autodeterminados e empenhados com o sentimento de solidariedade social, imprescindíveis para o projeto de construção de uma sociedade um pouco menos injusta para todos.

\section{REFERÊNCIAS DAS FONTES CITADAS}

DUARTE, Ícaro de Souza; CRUZES, Maria Soledade Soares. A metodologia da pesquisa no direito e Boaventura de Sousa Santos. In: PAMPLONA FILHO, Rodolfo; CERQUEIRA, Nelson (coord.). Metodologia da pesquisa em direito e a filosofia. São Paulo: Saraiva, 2011. pp. 164-180.

DURKHEIM, Émile. As regras do método sociológico. 2. ed. São Paulo: Martin Claret, 2001.

SANTOS, Boaventura de Sousa. Introdução a uma ciência pós-moderna. Rio de Janeiro: Graal, 1989. 
BECKER, Luciana Rosa. A metodologia da pesquisa no direito e o paradigma emergente de Boaventura de Sousa Santos. Revista Eletrônica Direito e Política, Programa de Pós-Graduação Stricto Sensu em Ciência Jurídica da UNIVALI, Itajaí, v.10, n.3, $2^{\circ}$ quadrimestre de 2015. Disponível em: www.univali.br/direitoepolitica - ISSN 1980-7791.

SANTOS, Boaventura de Souza. Para um novo senso comum: a ciência, o direito e a política na transição paradigmática. 5. ed. São Paulo: Cortez, 2005.

SANTOS, Boaventura de Sousa. Pela mão de Alice: o social e o político na pósmodernidade. 12 ed. São Paulo: Cortez, 2008.

SANTOS, Boaventura de Sousa. Um discurso sobre as ciências. 15 ed. Porto: Afrontamento, 2007.

Submetido em: Março/2015

Aprovado em: Maio/2015 